\title{
From Bees to Flies: Global Shift in Pollinator Communities Along Elevation Gradients
}

\author{
Lindsie M. McCabe ${ }^{1,2,3 *}$ and Neil S. Cobb ${ }^{2,3}$ \\ ${ }^{1}$ United States Department of Agriculture - Agriculture Research Service (USDA-ARS), Pollinating Insects Research Unit, \\ Logan, UT, United States, ${ }^{2}$ Biodiversity Outreach Network, Flagstaff, AZ, United States, ${ }^{3}$ Department of Biological Sciences, \\ Northern Arizona University, Flagstaff, AZ, United States
}

\section{OPEN ACCESS}

Edited by:

Pavel Kindlmann,

Charles University, Czechia

Reviewed by:

Adrian G. Dyer,

RMIT University, Australia

Stefan Dötterl,

University of Salzburg, Austria

*Correspondence:

Lindsie M. McCabe

lindsie.mccabe@gmail.com

Specialty section:

This article was submitted to

Population and Evolutionary

Dynamics,

a section of the journal

Frontiers in Ecology and Evolution

Received: 06 November 2020 Accepted: 22 December 2020

Published: 15 January 2021

Citation:

McCabe LM and Cobb NS (2021) From Bees to Flies: Global Shift in

Pollinator Communities Along

Elevation Gradients.

Front. Ecol. Evol. 8:626124.

doi: 10.3389/fevo.2020.626124
Bees decrease in abundance and richness along elevation gradients, while flies replace bees as the dominant flower visitors in higher elevation systems. We reviewed the existing literature to determine if this global phenomenon of pollinator communities switching from bees to flies occurs at the same place along a temperature gradient. Here we examined five studies that have documented this bee-to-fly transition in the North America, South America, Europe \& Australia. We determined where the bee-to-fly transition occurred along a temperature/elevation gradient for each study that ranged from 1.1 to $8.3^{\circ} \mathrm{C}$. We found that pollinator communities shifted from bee dominated to fly dominated communities between 4.9 and $5.7^{\circ} \mathrm{C}$ on all elevation gradients worldwide. This shift in pollinators could substantially impact ecological systems reliant on fly pollination as temperatures continue to warm.

Keywords: elevation gradient, bee (Apoidea), Diptera, climate change, biodiveristy, anthophila

\section{INTRODUCTION}

The rapid warming of the earth's atmosphere will likely change the makeup of all current ecosystems (IPCC, 2007). With the increase in temperature, ecological communities have started to change and are predicted to change even more in the coming years. Climate change, including warming temperatures, have already been documented to alter the fitness and range of species and therefore effecting community dynamics within an ecosystem (Gilman et al., 2010). Tree communities in the eastern United States have been shown to have a drastic reduction for some species; still, an increased species richness in other areas, leading to more resource competition between species in areas where new or introduced species establish (Iverson and Prasad, 2001). Species in high elevation environments might be the most susceptible to changes in community dynamics due to their isolated nature (Klanderud, 2005). Pollinators have an added stressor of climate change due to their strong biotic associations. It is predicted, while pollinator communities are likely to be buffered from phenological mismatch (i.e., plants and their pollinators responding to different climate signals), individual plant-pollinator interactions will vary widely (Hegland et al., 2009). Additionally, pollinators may be able to migrate north in latitude or altitude faster than their host plants creating another spatial mismatch between plants and their pollinators (Hegland et al., 2009). To understand how pollinator communities may respond to warming temperature, we need to assess the direct effects of warming temperature and indirect effect (i.e., phenological mismatch and nesting resources availability). 
Along elevation gradients, pollinator communities change from bee dominated to fly dominated communities (i.e., the beeto-fly transition). This fundamental observation is documented at a number of sites around the world where flies replace bees as the primary flower-visitor in high elevation environments (Arroyo et al., 1982; McCall, 1986; Kearns, 1992; Primack and Inouye, 1993; Lefebvre et al., 2018; McCabe et al., 2019b). Kearns (1992) suggested that this transition with increasing elevation was due to bees decreasing, while flies were not decreasing; therefore, they were able to occupy niche space that wasn't available at lower elevations. Inouye and Pike (1988) found that in Australia's snowy mountains, where bumblebees are not found, flies continued to increase along the elevation gradient while other orders declined. However, in the Rocky Mountains, bees do not decline as rapidly due primarily to the presence of 29 bumblebee species that exist at higher elevations (Inouye and Pike, 1988). It is possible that the decline in bee species and an increase in fly species along elevation gradients could be driven by temperature changes as elevation increases. Flies are known to increase in cold arctic environments, while other insect species declined (Strathdee and Bale, 1998). The increase in precipitation along an elevation gradient may also provide a more conducive habitat for flies than bees because many fly larval develop in moist or semi-aquatic/aquatic environments (McCabe et al., 2019a). Flies are typically thought of as less efficient pollinators than bees but can make up for the lack of efficiency by higher visitation rates (Kearns, 1992; Larson et al., 2001; Raguso, 2020). While bees primarily collect pollen for their larval brood, flies do not forage for their offspring; thus bees generally have a much stronger relationship with their floral hosts. There is evidence that bees are less common even at high elevations but still more important pollinators than flies (Bischoff et al., 2013). We examined five studies that have documented this bee-to-fly transition hypothesis in the North America, South America, Europe \& Australia. For each study, we determined where the bee-to-fly transition occurred along a temperature gradient between different geographical locations. This is the first review we are aware of that asks if this transition is a global phenomenon. It raises a number of questions regarding the drivers of this pattern and the implications of bee-to-fly transitions with regard to plant-pollinator relationships and angiosperm reproductive strategies.

\section{METHODS}

We queried Google Scholar for published studies that examined the change in pollinator communities along an elevation or altitude gradient. The initial search was conducted in March 2014 and then again in December 2019 using the following search terms (bee or bees or Apoideae or Apocrita or Anthophila) OR (fly or flies or Diptera) OR (Pollinator*) AND (elevation gradient OR altitudinal gradient). Our criteria for a study to be included in this analysis was (1) must have documented both bee and fly communities along an elevation gradient. (2) Provided the georeferenced locations of their sites or provided the elevation and general locality, and (3) reported the total abundance of both bees and flies or the percent of bees and flies for each location. Our final analysis included five studies that span three continents: North America, South America, Europe \& Australia (Arroyo et al., 1982; McCall, 1986; Primack and Inouye, 1993; Lefebvre et al., 2018; McCabe et al., 2019b).

For each study, we extracted the mean annual temperature (MAT) from the provided coordinated for each elevation sampled to corrector for latitudinal variation among locations. Mean annual temperature was extracted from WorldClim (average MAT from 1970 to 2000) data using the raster (Hijmans and van Etten, 2014) and sp (Pebesma and Bivand, 2005) package in R 3.1.2 (RCoreTeam, 2013). We extracted the data using the 30-s resolution. North American records were compared to PRISM data for studies that occurred outside the 30 -year average that WorldClim provides to make sure there were not anomalies in the years sampled. We ran a linear regression to test the relationship between the ratio (bee/fly) and temperature. The analysis was run using R 4.0.0 (RCoreTeam, 2013).

\section{RESULTS}

Regression analysis showed a significant linear relationship between the bee/fly ratio and mean annual temperature $\left(R^{2}\right.$ $=0.763, p<0.001)$. Linear fit indicated the switch from bee dominated communities to fly-dominated communities occurred at $5.28^{\circ} \mathrm{C}$. In each of these studies, the pollinator community was shown to switch from bee dominated communities at lower elevations to fly dominated communities at higher elevations. The transition from bee to fly communities is documented between 4.9 and $5.7^{\circ} \mathrm{C}$ for each study in this analysis; below $4.9^{\circ} \mathrm{C}$, the communities were fly dominated, and above $5.7^{\circ} \mathrm{C}$, the pollinator communities were bee dominated (Figure 1). This pattern is consistent for all studies examined in the North America, South America, Europe \& Australia.

These five studies examined this change in community composition between 600 and 3,600-meter along the elevation gradient. Two of the five studies had high, low, and midpoint(s) sampling, while the other three studies only had high and low points. Elevation ranged between 600 and 2,200 $\mathrm{m}$ for the low site and 1,922 and 3,600 m for the high elevation sites. Only 2 out of the five studies recorded data from middle elevations studies, ranging between 1,137 and $2,612 \mathrm{~m}$. While elevation varied between studies, mainly due to change in geographical location, the switch from bees to flies remained consistent at a narrow $1^{\circ} \mathrm{C}$ change between 5 and $6^{\circ} \mathrm{C}$ along these elevation gradients. We documented this change looking at abundance data since species richness data was only available for two out of the five studies. Even so, McCabe et al. (2019b) and Lefebvre et al. (2018) both showed the same bee-to-fly transition in abundance and species richness.

\section{DISCUSSION}

We found strong relationships for the bee-to-fly transition in these five studies; however, we were only able to examine areas with already documented pollinator diversity looking at 


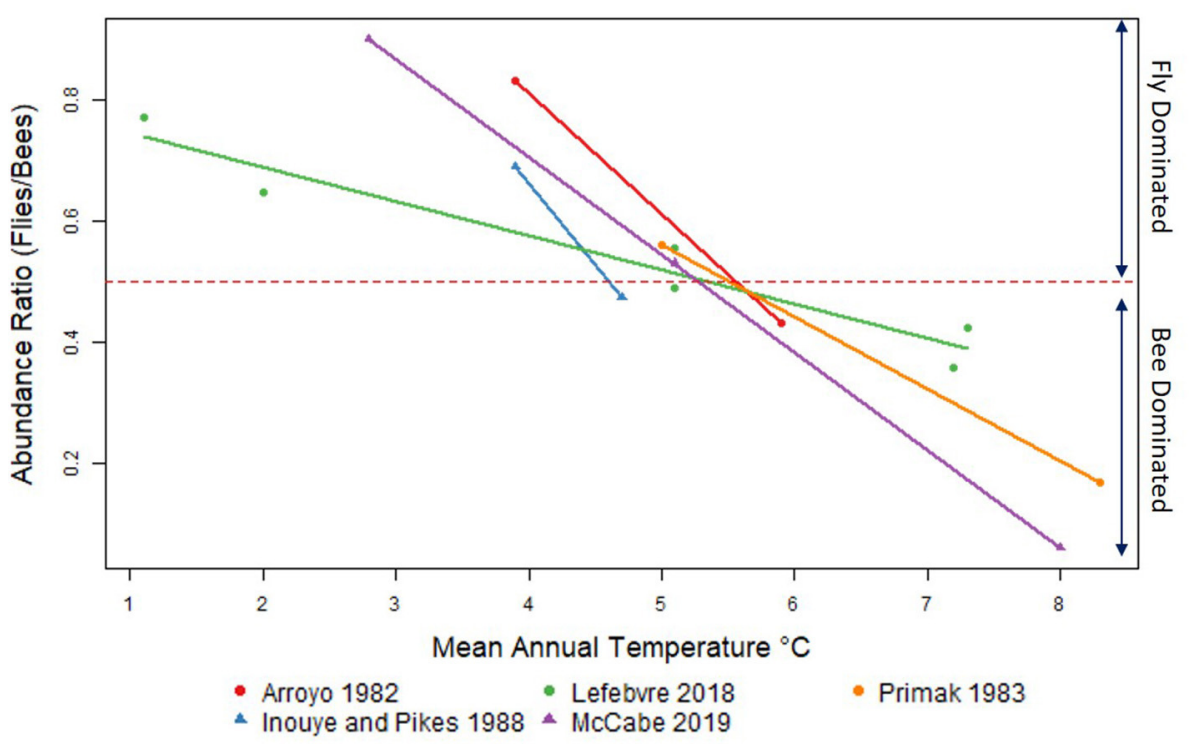

FIGURE 1 | Bee-to-fly transition in abundance along a temperature/elevation gradient. Temperature based on elevation with latitudinal correction. Insects are represented as the proportion abundance of all bees to all flies collected. The elevation range for these studies was 600-3,600 meters in the Andes, Chile (Arroyo et al., 1982), Canterbury, New Zealand (Primack, 1983), Snowy Mountain, Australia (Inouye and Pike, 1988), Southern Alps France (Lefebvre et al., 2018), and San Francisco Peaks, AZ, USA (McCabe et al., 2019b).

both bee and fly abundance. Subsequently, only one study examined other insects outside of bees and flies to see if the pollinator communities shifted to another taxa; Lefebvre et al. (2018) still documented fly-dominated communities at high elevations, even when assessing bees, butterflies, beetles, and flies. The San Francisco Peaks, AZ, also showed a lack of other dominant insect pollinators along that elevation gradient (McCabe unpublished data). As elevation increases, temperature decreases, and precipitation increases. This combination leads to a change in vegetation type and therefore influences the change in pollinator communities. Tree canopy cover may be influencing the change in community composition along elevation gradients. McCabe et al. (2019b) observed that when canopy cover is not present, the shift from bee-dominated to fly-dominated communities occurs higher in elevation. High humidity is also shown to change the abundance and diversity of bee and fly communities (Giannini et al., 2012). While we use temperature as our metric to account for a change in elevation due to geographical location, it is likely that a combination of factors is influencing this shift in pollinator communities.

While many of these studies examine the area where this transition would likely shift, we could not examine extreme environments (i.e., hot environments nor cool alpine environments). None of the five studies that documented the bee-to-fly transition occurred in warmer environments than $8^{\circ} \mathrm{C}$; we assume that temperatures above $8^{\circ} \mathrm{C}$ still bee dominant since pollinator communities are bee dominated in warm, arid environments (Danforth et al., 2019; Orr et al., 2020). Additionally, only one study examined these patterns above treeline to see if flies indeed remain the dominant pollinator. Their findings were consistent with this trend (Lefebvre et al.,
2018). All studies we are aware of have shown that flies are more prevalent in abundance, diversity, or both, while all studies at lower elevations have shown that bees dominate. Although these studies did not directly compare bees and flies along an elevation gradient, they are consistent with the results reported in our mini-review (Ssymank and Kearns, 2009; Lefebvre et al., 2014; Inouye, 2020).

The shift in dominant pollinator communities may have ecological implications that have not been considered. Although high elevation communities being fly dominated, flies may not be the most important pollinators in this ecosystem. Many studies have shown that flies, although frequent flower visitors, do not collect the pollen needed to pollinate flowers (Bischoff et al., 2013). Bischoff et al. (2013) found that in the New Zealand alpine that bees visited flowers less frequently than flies in the same community; however, the bees were doing most of the pollination. Additionally, in high elevation systems, flowers can be resorting to self-pollination rather than insect pollination due to the decrease in available insect pollinators (Berry and Calvo, 1989; Totland and Sottocornola, 2001). It is likely that some high elevation plants communities have adapted reproductive strategies that do not use insect pollinators (i.e., self or wind pollination). This change in pollinator communities along elevation could be driving changes in floral communities as well. Shrestha et al. (2001) showed that bumblebee pollination in high elevation environments influenced flower color signaling. Additionally, with increased climate warming, it is likely that communities will significantly shift in how pollinator communities are currently structured. Fly pollinators overall are likely to experience a reduction in range and response to warming temperatures and drying environments (Larson et al., 2001). 
Bees, however, could expand their range if the temperature is the main driving factor. All bees, however, may not respond the same way to warming temperatures. High elevation and cold adapted species such as bumble bees may have a much harder time adapting to warming temperatures (Biella et al., 2017). Given the strong biotic association, bees have with plants, it is unlikely that the change in temperature will be the only driving factor in the expansion or contraction of their range.

Despite the limited studies that have examined this phenomenon, we were able to document the general shift in bee to fly pollinators along an elevation gradient when mean annual temperatures are between 5 and $6^{\circ} \mathrm{C}$. Although this pattern holds true for all studies, those studies where only two sampling points exists, they could only show a linear relationship due to the nature of only having two points. As the earth continues to warm, whole pollinator communities are likely to shift, extending the usable range for bee species but limiting the suitable habitat available for fly pollinators. With the expected warming temperatures to be between 2 and $4^{\circ} \mathrm{C}$ by 2,080 , it is possible for this transition to shift up in elevation by $200-400$ meters. High elevation habitats and sharp gradients make mountain ecosystems vulnerable to slight changes in temperatures and extreme precipitation events (Kupfer and Cairns, 1996; Diaz et al., 2003). Many populations of both plants

\section{REFERENCES}

Arroyo, M. T. K., Primack, R., and Aremesto, J. (1982). Community studies in pollination ecology in the high temperate Andes of cental Chile I. Am. J. Bot. 69, 82-97. doi: 10.1002/j.1537-2197.1982.tb13237.x

Berry, P. E., and Calvo, R. N. (1989). Wind pollination, selfincompatibility, and altitudinal shifts in pollination systems in the high Andean genus Espeletia (Asteraceae). Am. J. Bot. 76, 1602-1614. doi: 10.1002/j.1537-2197.1989.tb15145.x

Biella, P., Bogliani, G., Cornalba, M., Manino, A., Neumayer, J., Porporato, M., et al. (2017). Distribution patterns of the cold adapted bumblebee Bombus alpinus in the Alps and hints of an uphill shift (Insecta: Hymenoptera: Apidae). J Insect Conserv. 21, 357-366. doi: 10.1007/s10841-017-9983-1

Bischoff, M., Campbell, D. R., Lord, J. M., and Robertson, A. W. (2013). The relative importance of solitary bees and syrphid flies as pollinators of two outcrossing plant species in the New Zealand alpine. Aust. Ecol. 38, 169-176. doi: 10.1111/j.1442-9993.2012.02389.x

Blois, J. L., Williams, J. W., Fitzpatrick, M. C., Jackson, S. T., and Ferrier, S. (2013). Space can substitute for time in predicting climatechange effects on biodiversity. Proc. Natl. Acad. Sci. 110, 9374-9379. doi: 10.1073/pnas.1220228110

Danforth, B. N., Minckley, R. L., Neff, J. L., and Fawcett, F. (2019). The Solitary Bees: Biology, Evolution, Conservation. Princeton, NJ: Princeton University Press.

Diaz, H., Eischeid, J., Duncan, C., and Bradley, R. (2003). "Variability of freezing levels, melting season indicators, and snow cover for selected high-elevation and continental regions in the last 50 years," in: Climate Variability and Change in High Elevation Regions: Past, Present \& Future, ed H. Diaz (Netherlands: Springer), 33-52.

Giannini, T. C., Acosta, A. L., Garófalo, C. A., Saraiva, A. M., Alves-dos-Santos, I., and Imperatriz-Fonseca, V. L. (2012). Pollination services at risk: bee habitats will decrease owing to climate change in Brazil. Ecol. Model. 244, 127-131. doi: 10.1016/j.ecolmodel.2012.06.035

Gilman, S. E., Urban, M. C., Tewksbury, J., Gilchrist, G. W., and Holt, R. D. (2010). A framework for community interactions under climate change. Trends Ecol. Evol. 25, 325-331. doi: 10.1016/j.tree.2010.03.002 and insects will likely move up in elevation rather than migrate to more northern latitudes (Rosenzweig et al., 2008). Species restricted to mountain tops (cold-adapted species), specialized to host plants, and dependent on biotic nesting resources are likely the most vulnerable to climate change. Elevation gradients act as great proxies to test climate change implications because we can replace time for space (Blois et al., 2013). This pattern of bees-to-flies along elevation gradients suggests that there may be a temperature limiting factor for bees in high elevation habitats. It is unknown how the influx of bee species to higher elevations would impact fly communities.

\section{DATA AVAILABILITY STATEMENT}

The original contributions generated for the study are included in the article/supplementary material, further inquiries can be directed to the corresponding author/s.

\section{AUTHOR CONTRIBUTIONS}

LM and NC contributed to the design and implementation of the research, to the analysis of the results and to the writing of the manuscript. Both authors contributed to the article and approved the submitted version.
Hegland, S. J., Nielsen, A., Lázaro, A., Bjerknes, A. L., and Totland, Ø. (2009). How does climate warming affect plant-pollinator interactions? Ecol. Lett. 12, 184-195. doi: 10.1111/j.1461-0248.2008.01269.x

Hijmans, R. J., and van Etten, J. (2014). raster: Geographic Data Analysis and Modeling. R package Version 2.

Inouye, D., and Pike, G. (1988). Pollination biology in the Snowy Mountians of Australia: comparison with montane Colorado, USA. Austr. J. Ecol. 13, 191-205. doi: 10.1111/j.1442-9993.1988.tb00968.x

Inouye, D. W. (2020). Effects of climate change on alpine plants and their pollinators. Ann. N. Y. Acad. Sci. 1469, 26-37. doi: 10.1111/nyas.14104

IPCC (2007). Climate Change 2007: The Physical Science Basis. in: Contribution of Working Group I to the Fourth Assessment Report of the Intergovernmental Panel on Climate Change, eds S. Solomon, D. Qin, M. Manning, Z. Chen, M. Marquis, K. B. Averyt, et al. (Cambridge; New York, NY: Cambridge University Press).

Iverson, L. R., and Prasad, A. M. (2001). Potential changes in tree species richness and forest community types following climate change. Ecosystems 4, 186-199. doi: 10.1007/s10021-001-0003-6

Kearns, C. (1992). Anthophilous fly distribution across an elevation gradient. Am. Midl. Nat. 127, 172-182. doi: 10.2307/2426332

Klanderud, K. (2005). Climate change effects on species interactions in an alpine plant community. J. Ecol. 93, 127-137. doi: 10.1111/j.1365-2745.2004. 00944.x

Kupfer, J. A., and Cairns, D. M. (1996). The suitability of montane ecotones as indicators of global climatic change. Prog. Phys. Geogr. 20, 253-272. doi: 10.1177/030913339602000301

Larson, B. M. H., Kevan, P. G., and Inouye, D. (2001). Flies and flowers: taxonomic diversity of anthophiles and pollinators. Can. Entomol. 133, 439-465. doi: 10.4039/Ent133439-4

Lefebvre, V., Fontaine, C., Villemant, C., and Daugeron, C. (2014). Are empidine dance flies major flower visitors in alpine environments? A case study in the Alps, France. Biol. Lett. 10:20140742. doi: 10.1098/rsbl.2014.0742

Lefebvre, V., Villemant, C., Fontaine, C., and Daugeron, C. (2018). Altitudinal, temporal and trophic partitioning of flower-visitors in Alpine communities. Sci. Rep. 8:4706. doi: 10.1038/s41598-018-23210-y

McCabe, L. M., Cobb, N. S., and Butterfield, B. J. (2019a). Environmental filtering of body size and darker coloration in pollinator communities indicate 
thermal restrictions on bees, but not flies, at high elevations. PeerJ 7:e7867. doi: $10.7717 /$ peerj. 7867

McCabe, L. M., Colella, E., Chesshire, P., Smith, D., and Cobb, N. S. (2019b). The transition from bee-to-fly dominated communities with increasing elevation and greater forest canopy cover. PLoS ONE 14:e0217198. doi: 10.1371/journal.pone.0217198

McCall, C. (1986). Plant Reproductive Ecology at Community and Population Levels: A Comparative Study in 3 Communities. Boston: Boston University, 221.

Orr, M. C., Hughes, A. C., Chesters, D., Pickering, J., Zhu, C.-D., and Ascher, J. S. (2020). Global patterns and drivers of bee distribution. Curr. Biol 31, 1-8. doi: 10.1016/j.cub.2020.10.053

Pebesma, E., and Bivand, R. S. (2005). S Classes and Methods for Spatial Data: The sp Package, Vol. 5. R news, 9-13.

Primack, R., and Inouye, D. (1993). Factors affecting pollinator visitation rates: a biogeographical comparison. Curr. Sci. 63, 257-261.

Primack, R. B. (1983). Insect pollination in the New Zealand mountain flora. New Zealand J. Botany, 21, 317-333. doi: 10.1080/0028825X.1983.10428561

Raguso, R. A. (2020). Don't forget the flies: dipteran diversity and its consequences for floral ecology and evolution. Appl. Entomol. Zool. 55, 1-7. doi: 10.1007/s13355-020-00668-9

RCoreTeam (2013). R: A Language and Environment for Statistical Computing. RCoreTeam.

Rosenzweig, C., Karoly, D., Vicarelli, M., Neofotis, P., Wu, Q., Casassa, G., et al. (2008). Attributing physical and biological impacts to anthropogenic climate change. Nature 453:353. doi: 10.1038/nature06937
Shrestha, M., Dyer, A. G., Bhattarai, P., and Burd, M. (2001). Flower colour and phylogeny along an altitudinal gradient in the $\mathrm{H}$ imalayas of $\mathrm{N}$ epal. J. Ecol. 102, 126-135. doi: 10.1111/1365-2745.12185

Ssymank, A., and Kearns, C. (2009). Flies-Pollinators on Two Wings. Caring for Pollinators: Safeguarding Agrobiodiversity and Wild Plant Diversity. Bonn: Bundesamt für Naturschutz, German Federal Agency for Nature Conservation, 39-52.

Strathdee, A., and Bale, J. (1998). Life on the edge: insect ecology in arctic environments. Annu. Rev. Entomol. 43, 85-106. doi: 10.1146/annurev.ento.43.1.85

Totland, Ø., and Sottocornola, M. (2001). Pollen limitation of reproductive success in two sympatric alpine willows (Salicaceae) with contrasting pollination strategies. Am. J. Bot. 88, 1011-1015. doi: 10.2307/26 57082

Conflict of Interest: The authors declare that the research was conducted in the absence of any commercial or financial relationships that could be construed as a potential conflict of interest.

Copyright (๑) 2021 McCabe and Cobb. This is an open-access article distributed under the terms of the Creative Commons Attribution License (CC BY). The use, distribution or reproduction in other forums is permitted, provided the original author(s) and the copyright owner(s) are credited and that the original publication in this journal is cited, in accordance with accepted academic practice. No use, distribution or reproduction is permitted which does not comply with these terms. 